\title{
The FNR modules contribute to control nitric oxide synthase catalysis revealed by chimera enzymes
}

\author{
RUIQIANG WANG ${ }^{1}$, BIYUE WANG ${ }^{1}$, BOWEN ZHENG ${ }^{1}$, PUPU MA ${ }^{1}$, RONG GOU ${ }^{1}$, YUANYUAN GUO ${ }^{1}$,

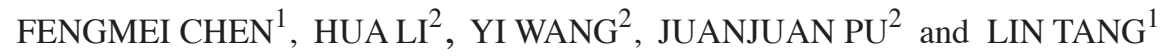 \\ Departments of ${ }^{1}$ Nephrology and ${ }^{2}$ Gerontology, The First Affiliated Hospital of \\ Zhengzhou University, Zhengzhou, Henan 450052, P.R. China
}

Received July 6, 2017; Accepted September 28, 2017

DOI: $10.3892 / \mathrm{mmr} .2017 .7745$

\begin{abstract}
The reductase domains of neuronal NOS, endothelial NOS and two constitutive nitric oxide synthase (cNOS) share higher sequence similarity $(>60 \%)$. In order to evaluate the role of ferredoxin-NADP ${ }^{+}$reductase (FNR) module in adjusting NOS catalytic activities, chimeras were by interchanging the FNR-like module between endothelial NOS and neuronal NOS in the present study. The assays of steady-state enzymatic activities for cytochrome $c$ and ferricyanide reduction, NO synthesis and NADPH oxidation were performed spectrophotometrically. The two NOS FNR modules transferred their ferricyanide reductase character to the chimera enzymes. Results showed that the FNR module was important in adjusting electrons flow through the reductase domain and out of the FMN module. Results indicated that the FNR module was critical in controlling the electron transfer capacities of the FMN module.
\end{abstract}

\section{Introduction}

Nitric oxide (NO) is synthesized by the NO synthase (NOS) enzyme. NO is a cytotoxin and a ubiquitous signaling molecule $(1,2)$. Nitric oxide synthases (NOSs) are hemoproteins

Correspondence to: Dr Ruiqiang Wang or Dr Lin Tang, Department of Nephrology, The First Affiliated Hospital of Zhengzhou University, 1 Jianshe East Road, Zhengzhou, Henan 450052, P.R. China

E-mail: wangruiqiang@zzu.edu.cn

E-mail:wryjmn@163.com

Abbreviations: NO, nitric oxide; NOS, NO synthase; eNOS, endothelial NOS; nNOS, neuronal NOS; cNOS, constitutive NOS (nNOS and eNOS); NOSred, reductase domain of NOS; FNR, ferredoxin-NADP ${ }^{+}$reductase; $\mathrm{nNOS}_{\mathrm{eFNR}}$, nNOS incorporates with eNOS FNR module; eNOS $_{\mathrm{nFNR}}$, eNOS incorporates with nNOS FNR module; EPPS, 4-(2-hydroxyethyl)-1-piperazinepropanesulfonic acid; CaM, calmodulin; EGTA, ethylene glycol tetraacetic acil; IPTG, isopropyl- $\beta$-D-thiogalactopyranoside; PMSF, phenylmethylsulphonyl fluoride.

Key words: chimera enzyme, nitric oxide synthase, electron transfer and catalyze the oxidation of arginine to nitric oxide (NO) and citrulline. Three genetically and functionally distinct NOS isoforms, endothelial NOS (eNOS), inducible NOS (iNOS) and neuronal NOS (nNOS) have been identified from endothelial cells, microphages and neurons, respectively $(3,4)$. NOSs are incorporate three domains in a single polypeptide: i) The N-terminal P450-like oxygenase domain that binds heme, tetrahydrobiopterin $\left(\mathrm{H}_{4} \mathrm{~B}\right)$, and L-arginine, is the site of oxidation of arginine; ii) a C-terminal cytochrome $\mathrm{P} 450$ reductase (CPR)-related reductase domain that contains binding sites for FAD, FMN and NADPH, is responsible for providing electrons to the oxygenase domain; iii) a connecting peptide between the two domains binds calmodulin in a $\mathrm{Ca}^{2+}$-dependent manner for constitutive NOS (cNOS), nNOS and eNOS and essentially $\mathrm{Ca}^{2+}$-independent manner in iNOS $(1,3,5-9)$. Regulation of NOS activity by $\mathrm{CaM}$ has been shown to occur via the control of electron transfer chain in NOS (NADPH ${ }^{\circledR}$ FAD ${ }^{\circledR}$ FMN ${ }^{\circledR}$ Heme) across the domain-domain interaction $(10,11)$. It was shown that CaM can activate NADPH-dependent flavin reduction by suppressing the repressors within reductase domain, such as a C-terminal tail (CT) (12-14) and an autoinhibitory insert (AI) (15-17) within the middle of FMN sub-domain of cNOS.

NOS reductase domain can be dissected into two domains: The N-terminal FMN binding domain is homologous to bacterial flavodoxin, and the C-terminal fragment, containing binding sites for NADPH and FAD is related to the ferredoxin-NADP ${ }^{+}$reductase (FNR) (18). Each flavin nucleotide in NOS plays an obvious role in the electron flow sequence: FAD can transfer NADPH-divided electrons to linked FMN or exogenous electron acceptors such as ferricyanide and 3-acetylpypyridine adenine dinucleotide phosphate $\left(\mathrm{AcPyADP}^{+}\right)$, and the FMN can transfer the electrons to attached heme or non-physiological acceptors such as cytochrome $c(19,20)$. It has been demonstrated that each of the recombinant flavin-binding domains can be expressed separately and retains the chemical and catalytic properties of their native counterparts (19-21). Recent reported crystal structures of rat nNOS reductase domain and mutation studies suggested that a movement of the FMN module from FNR may be required for its optimal position to transfer electron out of FMN (18). Crystal structure studies of the sulfite 
reductase indicated that the interaction between the FNR and FMN modules displays lower affinity than in the case of CPR (22). FMN-free mutant studies suggested that removing FMN relieved suppression of FAD reduction within the FNR module and increase ferricyanide reduction (23). These data established the importance of domain-domain interaction and domain movement in flavoprotein catalysis.

The two constitutive NOS, eNOS and nNOS share similarities both in their structure and biochemical behaviors. However, nNOS exhibits much higher overall enzymatic activities than eNOS $(24,25)$. Investigations of chimera enzymes that possess exchanged oxygenase and reductase domain indicated that heme reduction rate in cNOS is controlled mainly by the reductase domains (25). The heme reduction rate is almost independent of oxygenase domain (25). Previous results showed that the lower intrinsic activity of eNOS is caused by a lower ability of its electron transfer rate to the catalytic heme domain or external acceptors (26), but the NADPH-dependent flavin reduction rates of both CaM-bound cNOS are similar (27). Results showed that the electron transfer from full-reduced FMN $\left(\mathrm{FMNH}_{2}\right)$ to heme or cytochrome $c$ in cNOS is primarily influenced through a mechanism that does not involve changing the rate of flavins reduction. The details are not clear. it was suspected that the interaction of the FNR and FMN modules may differ between nNOS and eNOS. In this work, we will investigate how electron transfer and catalysis is related to the domain-domain interaction.

In the present study, we have constructed chimeric NOS enzymes by interchanging the FNR module between the two cNOS, and have studied the consequence of FNR module on catalytic activities, electron transfer properties by spectral methods. Our results clearly indicated that FNR module is important in controlling electron flow through the reductase domain to attached heme and outside from FMN module.

\section{Materials and methods}

Materials. His-binding resin and CaM-sepharose were products of Amersham Biosciences (Uppsala, Sweden). Cytochrome $c$ was purchased from Sigma (St. Louis, MO, USA). Restriction enzymes were purchased from New England Bio-lab (Ipswich, MA, USA). All other chemicals were purchased from Sigma-Aldrich (St. Louis, MO, USA).

Generation of chimera DNAs. The original vector coding was a gift to R.W. from Professor Philip Marsden (University of Toronto, Canada). Briefly, a unique restriction site Nru I was generated at S866 and R877 for nNOS, and S656 and R657 for eNOS by Site-directed mutagenesis using Quick Change polymerase chain reaction (PCR) in vitro mutagenesis kit from Stratagene (Agilent Technologies, Inc., Santa Clara, CA, USA).

Expression and purification of chimera and wild-type enzymes. Like wild-type rat nNOS and bovine eNOS, the chimera enzymes containing a His- 6 tag attached to their $\mathrm{N}$-termini were over-expressed in E. coli BL21 and purified by sequential chromatograph on $\mathrm{Ni}^{2+}$-NTA and Calmodulin-sepharose resins $(28,29)$. The ferrous- $\mathrm{CO}$ adduct absorbing at $444 \mathrm{~nm}$ was used to quantitative heme protein content using an extinction
Table I. NADPH oxygenase activities of native and chimeric enzymes.

\begin{tabular}{lcccc}
$\begin{array}{l}\mathrm{CaM} / \mathrm{Arg} \text { or } \\
\mathrm{Aga} / \mathrm{H}_{4} \mathrm{~B}\end{array}$ & nNOS & eNOS & nNOS $_{\mathrm{eFNR}}$ & eNOS $_{\mathrm{nFNR}}$ \\
\hline$-/ \mathrm{Arg} /+$ & $8.0 \pm 0.5$ & $4.8 \pm 0.6$ & $2.4 \pm 0.1$ & $22 \pm 1.0$ \\
$+/ \mathrm{Aga} /+$ & $27 \pm 3.0$ & $11 \pm 1.5$ & $5.9 \pm 0.5$ & $27 \pm 2.0$ \\
$+/ \mathrm{Arg} /+$ & $117 \pm 10$ & $33 \pm 2.0$ & $15 \pm 1.0$ & $37 \pm 2.0$ \\
\hline
\end{tabular}

All values are the mean \pm standard error for three separate determinations. All reactions were performed at $25^{\circ} \mathrm{C}$. Arg, Arginine; Aga, Agatine; eNOS, endothelial nitric oxide synthase; nNOS, neuronal nitric oxide synthase; FNR, ferredoxin-NADP ${ }^{+}$reductase.

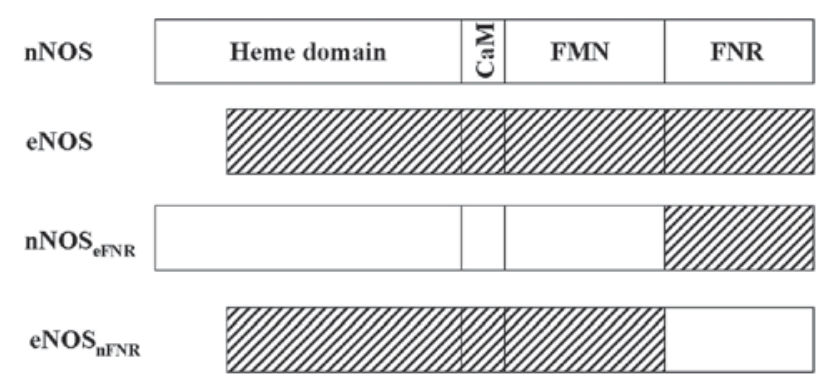

Figure 1. Illustration of constructed nNOS and eNOS chimeras. The open bar represents the nNOS and the black bar represents the eNOS. eNOS, endothelial nitric oxide synthase; nNOS, neuronal nitric oxide synthase; FNR, ferredoxin-NADP ${ }^{+}$reductase.

coefficient of $74 \mathrm{mM} / \mathrm{cm}$. The contents of FAD and FMN were measured by HPLC with fluorometric detection.

Spectrophotometric methods. The assays of steady-state enzymatic activities for ferricyanide and cytochrome $c$ reduction, NO synthesis, and NADPH oxidation were carried out spectrophotometrically. The rates of ferricyanide reduction were obtained by determining the absorbance decrease at $420 \mathrm{~nm}$ using an extinction coefficient of $1.02 \mathrm{mM} / \mathrm{cm}$. The concentration of ferricyanide and NADPH was $1.0 \mathrm{mM}$ and $0.3 \mathrm{mM}$, respectively. Cytochrome $c$ reduction was determined by monitoring the absorbance increasement at $550 \mathrm{~nm}$ using a difference extinction coefficient of $21 \mathrm{mM} / \mathrm{cm}$ between reduced and oxidized forms, with $0.3 \mathrm{mM} \mathrm{NADPH}$ and $0.1 \mathrm{mM}$ cytochrome $c$. The rate of NADPH oxidation was measured by monitoring the absorbance decrease at $340 \mathrm{~nm}$ using an extinction coefficient of $6.22 \mathrm{mM} / \mathrm{cm}$ with $0.1 \mu \mathrm{M}$ NADPH and in the presence or absence of $5 \mu \mathrm{M} \mathrm{CaM}, 300 \mu \mathrm{M}$ $\mathrm{Ca}^{2+}, 10 \mu \mathrm{M} \mathrm{H}_{4} \mathrm{~B}, 250 \mu \mathrm{M}$ Arginine or Agatine. NO synthesis rate was monitored from the conversion of oxyhemoglobin to methemoglobin mediated by NO. The rate was obtained by using a difference extinction coefficient of $38 \mathrm{mM} / \mathrm{cm}$ between oxyhemoglobin and methemoglobin at $401 \mathrm{~nm}$, with $0.3 \mathrm{mM}$ NADPH, $4 \mu \mathrm{M} \mathrm{H}_{4} \mathrm{~B}, 10 \mu \mathrm{M}$ oxyhemoglobin and $1 \mathrm{mM}$ $\mathrm{L}$-arginine. All results were obtained at $25^{\circ} \mathrm{C}$ in EPPS buffer (40 mM, pH 7.6) containing $0.25 \mathrm{M} \mathrm{NaCI}, 10 \%$ glycerol, 10 units/ml superoxide dismutase (SOD), $0.5 \mu \mathrm{M}$ FAD/FMN, 100 units $/ \mathrm{ml}$ catalase, and $50 \mu \mathrm{M}$ EDTA (for minus CaM assays) using a U-3110 spectrophotometer (HITACHI Ltd, 

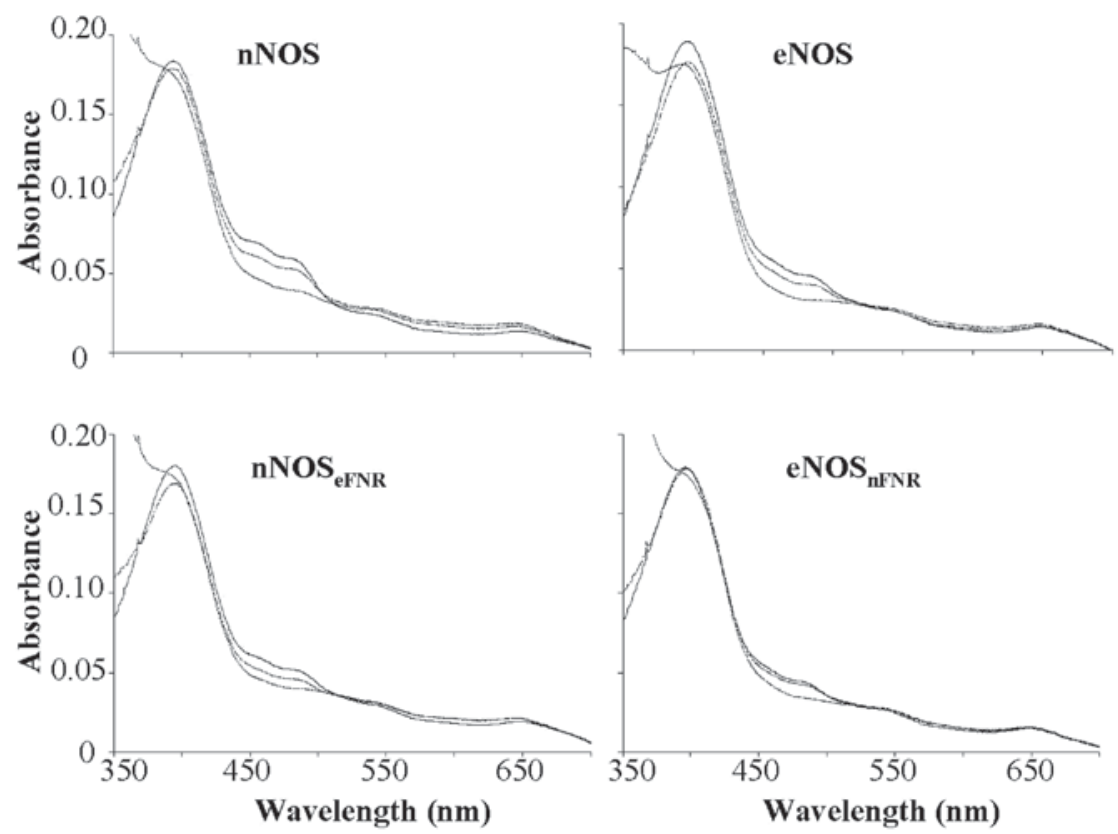

Figure 2. Absorbance spectra record during oxidation-reduction reactions of wild-type and chimera enzymes. (-) The oxidized enzymes. (....) The spectra were recorded immediately after mixing excess NADPH with enzyme. (---) The spectra were recorded at 30 min after addition of excess NADPH to enzyme solution. Final concentrations: Enzyme, $1.8 \mu \mathrm{M}$; NADPH, $100 \mu \mathrm{M}$; CaM, $5 \mu \mathrm{M}$; Ca ${ }^{2+}, 300 \mu \mathrm{M} ; \mathrm{H}_{4} \mathrm{~B}, 10 \mu \mathrm{M}$; Agatine, $250 \mu \mathrm{M}$. Results are representative of three similar individual experiments. nNOS, neuronal nitric oxide synthase; H4B, tetrahydrobiopterin; eNOS, endothelial nitric oxide synthase; FNR, ferredoxin-NADP ${ }^{+}$reductase.

Tokyo, Japan). For assays of calmodulin activation, $5 \mu \mathrm{M}$ $\mathrm{CaM}$ and $0.5 \mathrm{mM} \mathrm{Ca}^{2+}$ were added to the reaction mixture, respectively.

Kinetics of NADPH-dependent flavin and heme reduction. Rapid mixing stopped-flow reaction were performed using a stopped-flow spectrophotometer. The stopped-flow apparatus had a dead time of $2 \mathrm{~ms}$ and was equipped with an anaerobic workbox. Stopped-flow experiments were obtained in $0.25 \mathrm{M}$ $\mathrm{NaCl}, 40 \mathrm{mM}$ pH 7.6 EPPS buffer. The constant temperature is $10^{\circ} \mathrm{C}$. Flavin reduction was measured by monitoring the decrease of absorbance (485 nm) after mixing $50 \mu \mathrm{M}$ NADPH with $2 \mu \mathrm{M}$ enzyme in the presence and absence of $\mathrm{Ca}^{2+} / \mathrm{CaM}$ under anaerobic conditions. Anaerobic heme reduction rate was obtained by monitoring the increase of absorbance at $444 \mathrm{~nm}$, and this rate represents the formation of ferrous-CO complex. Reaction was initiated by rapid mixing $50 \mu \mathrm{M}$ NADPH with $2 \mu \mathrm{M}$ chimera or wild-type in $40 \mu \mathrm{M}$ EPPS buffer, $\mathrm{pH} 7.6,10 \mu \mathrm{M} \mathrm{H}_{4} \mathrm{~B}, 1 \mathrm{mM}$ L-arginine, $10 \mu \mathrm{M} \mathrm{CaM}$, and $1 \mathrm{mM} \mathrm{Ca}^{2+}$. In these experiments, NADPH, chimera and wild-type were prepared in an anaerobic CO-saturated solutions.

\section{Results}

Expression and purification of chimera enzymes. FNR swapped chimera enzymes, NNOS $_{\text {eFNR }}$ and NOS $_{\mathrm{nFNR}}$ were expressed in E. coli BL21. Their yields were similar to those of wild-type nNOS and eNOS, respectively. The chimera enzymes were purified in the same way as wild-type enzymes as described in experiment procedures. Both the chimera enzymes showed correct molecular mass and over $90 \%$ purity as judged by SDS-PAGE. The chimera enzymes (Fig. 1) contained 1 FMN and 1 FAD per NOS heme measured by HPLC.

Optical spectra properties of chimera enzymes. Spectroscopic analysis showed that the chimera enzymes were consistent with the flavins-bound wild-type proteins as shown in Fig. 2 spectrum a. Dithionite reduction of the chimera enzymes produced the expected absorbance peak at $444 \mathrm{~nm}$ for the ferrous-CO complex in all cases in the presence of Arg, $\mathrm{H}_{4} \mathrm{~B}$ and $\mathrm{CO}$. Results indicated that swapped FNR sub-domain between nNOS and eNOS did not alter proteins folding, expression and physical properties.

NADPH oxidation. The steady-state oxidation of NADPH was measured in the presence or absence of $\mathrm{CaM}$, Arginine or Agatine, $\mathrm{H}_{4} \mathrm{~B}$ as shown in Fig. 3 and Table I. Compared with wild-type nNOS, the chimera enzyme, NNOS $_{\text {eFNR }}$ showed a lower (approximately 12-30 \%) NADPH oxygenase activity both in the presence and absence of CaM. In contrast, the chimera enzyme, eNOS $_{\mathrm{nFNR}}$ showed higher $(\sim 4.5$-fold $)$ NADPH oxygenase activity than that of wild-type eNOS without CaM. However, unlike NNOS $_{\mathrm{eFNR}}$, it did not increase upon CaM.

NO synthesis. The binding of CaM is essential for electron transfer from FMN to heme thereby initiated NO synthesis. Wild-type nNOS showed higher ability of NO synthesis ( $\sim 5$-fold) than that of wild-type eNOS. We measured the steady-state NO synthesis of chimera enzymes as shown in Fig. 4 and Table II. As the wild-type enzymes, both chimera enzymes are required CaM binding for $\mathrm{NO}$ synthesis activity. The nNOS chimera $\left(\mathrm{nNOS}_{\mathrm{eFNR}}\right)$ incorporates eNOS FNR module and showed NO synthesis activity that was about $12 \%$ 
Table II. Steaty-state activities for NO synthesis, cyt. $c$ reduction and ferricyanide reduction.

\begin{tabular}{lccccrr}
\hline & \multicolumn{2}{c}{ NO synthesis } & & \multicolumn{2}{c}{ Cyt. $c$ reduction } & \multicolumn{2}{c}{ Ferricyanide reduction } \\
\cline { 2 - 6 } & - & + & - & + & - \\
\hline nNOS & ND & $51 \pm 4.4$ & $554 \pm 13$ & $4,798 \pm 148$ & $7,800 \pm 508$ \\
eNOS & ND & $11 \pm 0.9$ & $63 \pm 4$ & $340 \pm 10$ & $6,012 \pm 165$ & $11,983 \pm 745$ \\
nNOS $_{\text {eFNR }}$ & ND & $6.3 \pm 0.3$ & $59 \pm 4.0$ & $151 \pm 14$ & $6,349 \pm 312$ & $6,665 \pm 100$ \\
eNOS $_{\text {nFNR }}$ & ND & $13 \pm 1.0$ & $787 \pm 42$ & $562 \pm 32$ & $8,366 \pm 194$ & $8,627 \pm 131$
\end{tabular}

NO, nitric oxide; eNOS, endothelial nitric oxide synthase; nNOS, neuronal nitric oxide synthase; FNR, ferredoxin-NADP ${ }^{+}$reductase.

Table III. Observed rate constants for NADPH-dependent flavin and heme reduction in the presence and $\mathrm{absence} \mathrm{of} \mathrm{Ca}^{2+} / \mathrm{CaM}^{2}$ $\left(10^{\circ} \mathrm{C}\right)$.

\begin{tabular}{|c|c|c|c|}
\hline & \multicolumn{2}{|c|}{ Flavin reduction } & \multirow{2}{*}{$\frac{\text { Heme reduction }}{\mathrm{k}}$} \\
\hline & $\mathrm{k} 1(\%)$ & $\mathrm{k} 2$ & \\
\hline nNOS & $\begin{array}{l}-4.3 \pm 0.2(63) \\
+48 \pm 2.1(61)\end{array}$ & $\begin{array}{c}0.4 \pm 0.02 \\
5.1 \pm 0.004\end{array}$ & $\begin{array}{c}\mathrm{ND} \\
3.6 \pm 0.2\end{array}$ \\
\hline eNOS & $\begin{array}{l}-0.3 \pm 0.03(59) \\
+59 \pm 4.4(77)\end{array}$ & $\begin{array}{c}0.02 \pm 0.002 \\
4.3 \pm 0.9\end{array}$ & $\begin{array}{c}\text { ND } \\
0.005 \pm 0.0004\end{array}$ \\
\hline $\mathrm{nNOS}_{\mathrm{eFNR}}$ & $\begin{array}{c}-0.17 \pm 0.003(40) \\
+19 \pm 3.5(43)\end{array}$ & $\begin{array}{c}0.019 \pm 0.0007 \\
0.19 \pm 0.006\end{array}$ & $\begin{array}{c}\text { ND } \\
0.0018 \pm 0.0002\end{array}$ \\
\hline $\mathrm{eNOS}_{\mathrm{nFNR}}$ & $\begin{array}{l}-18 \pm 1.0(62) \\
+32 \pm 1.7(64)\end{array}$ & $\begin{array}{l}1.0 \pm 0.02 \\
1.1 \pm 0.03\end{array}$ & $\begin{array}{c}\text { ND } \\
0.0024 \pm 0.0002\end{array}$ \\
\hline
\end{tabular}

NOS, neuronal nitric oxide synthase; eNOS, endothelial nitric oxide synthase; FNR, ferredoxin-NADP ${ }^{+}$reductase.
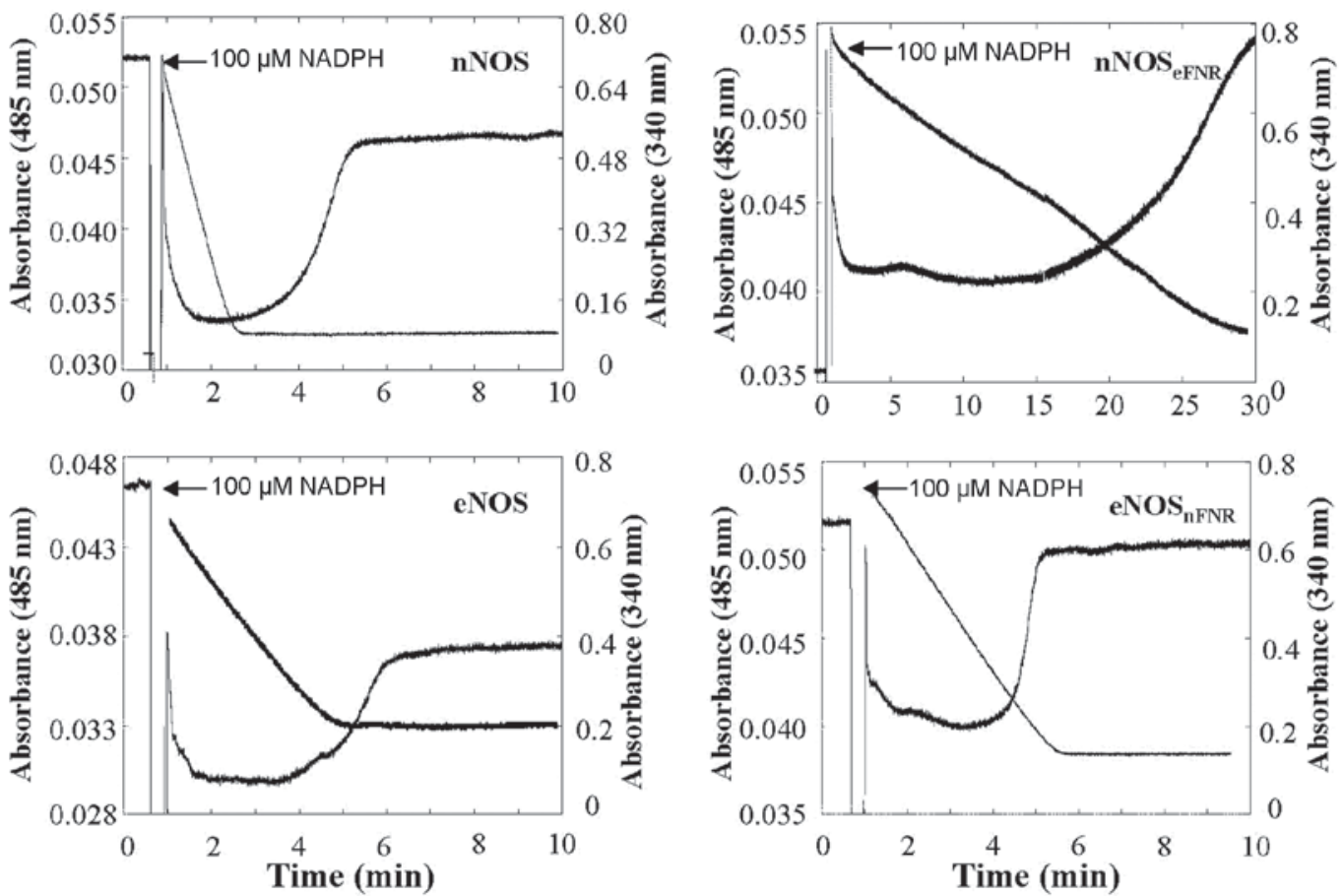

Figure 3. Time course of absorbance change at $485 \mathrm{~nm}$ represent flavin oxidation-reduction, and at $340 \mathrm{~nm}$ represents NADPH oxidation, respectively. The enzyme solution contain: Enzyme, $1.8 \mu \mathrm{M} ; \mathrm{CaM}, 5 \mu \mathrm{M} ; \mathrm{Ca}^{2+}, 300 \mu \mathrm{M} ; \mathrm{H}_{4} \mathrm{~B}, 10 \mu \mathrm{M}$; Aratine, $250 \mu \mathrm{M}$. The narrows indicate the point of addition of $100 \mu \mathrm{M}$ NADPH. Results are representative of three similar individual experiments. H4B, tetrahydrobiopterin; eNOS, endothelial nitric oxide synthase; FNR, ferredoxin-NADP ${ }^{+}$reductase. 


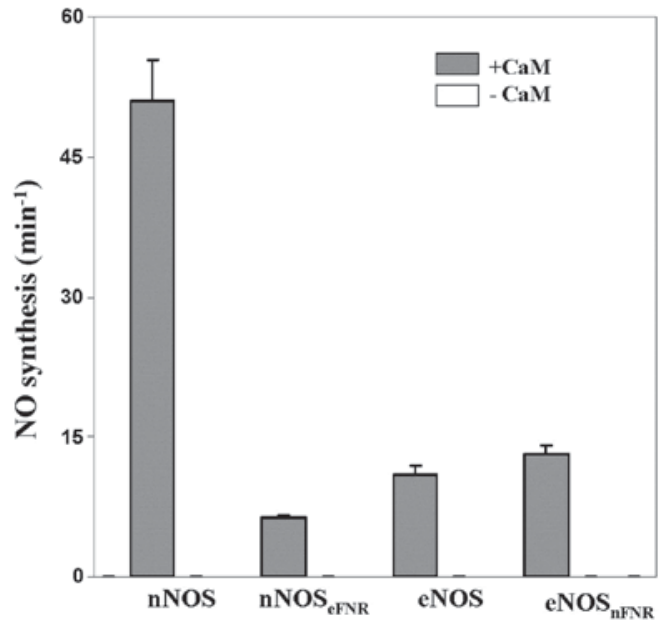

Figure 4. Steady-state NO formation of wild-type and chimera enzymes in the absence and presence of $\mathrm{CaM} / \mathrm{Ca}^{2+}$ as described in Materials and methods. Each bar represents the mean \pm standard error of three independent measurements. NO, nitric oxide; nNOS, neuronal NO synthase; eNOS, endothelial NO synthase; FNR, ferredoxin-NADP ${ }^{+}$reductase.

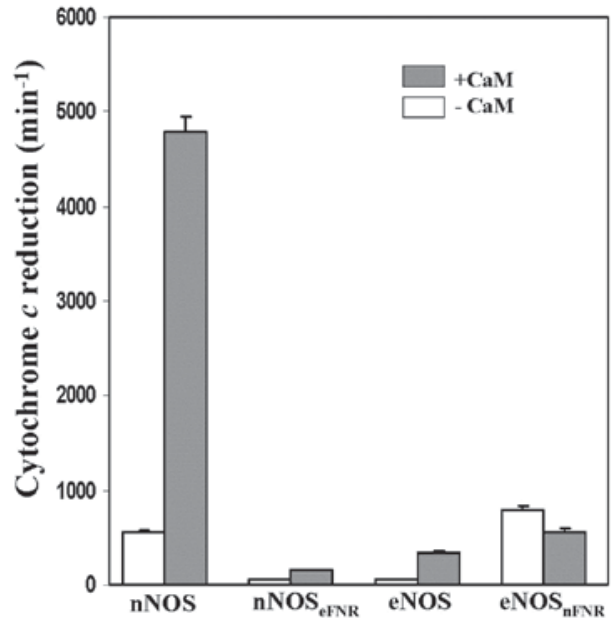

Figure 5. Steady-state cytochrome $c$ reduction of wild-type and chimera enzymes. The activities of cytochrome $c$ were measured in the absence and presence of $\mathrm{CaM} / \mathrm{Ca}^{2+}$ as described in Materials and methods. Each bar represents the mean \pm standard error of three independent measurements. nNOS, neuronal NO synthase; eNOS, endothelial NO synthase; FNR, ferredoxin-NADP ${ }^{+}$reductase.
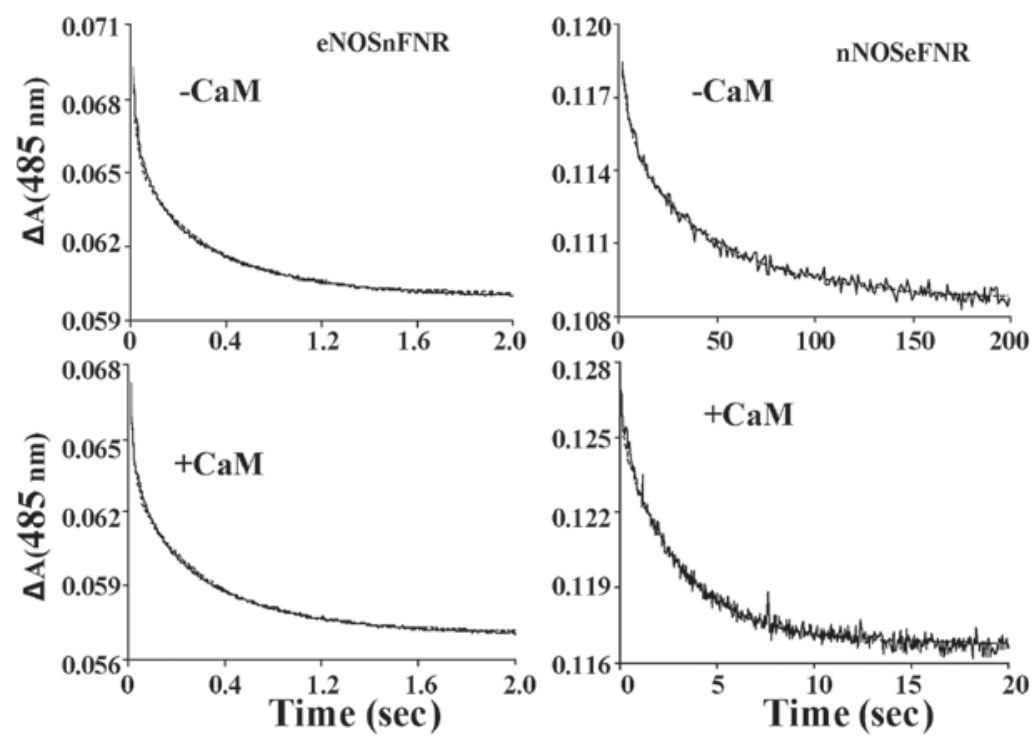

Figure 6. Kinetics of NADPH-dependent flavin reduction in chimera enzymes, NOS $_{\mathrm{nFNR}}$ and nNOS ${ }_{\mathrm{eFNR}}$ in the absence and presence of CaM/Ca ${ }^{2+}$. Spectral changes were recorded at $485 \mathrm{~nm}$ represent the flavin reduction in a stopped-flow spectrophotometer after rapid mixing $2 \mu \mathrm{M}$ enzyme and $50 \mu \mathrm{M}$ NADPH in $40 \mathrm{mM}$ EPPS buffer containing $0.25 \mathrm{M} \mathrm{NaCl}, \mathrm{pH} 7.6$, under anaerobic conditions at $10^{\circ} \mathrm{C}$. Traces shown are the average of $8-10$ individual scans. $\mathrm{nNOS}$, neuronal NO synthase; eNOS, endothelial NO synthase; FNR, ferredoxin-NADP ${ }^{+}$reductase.

of native nNOS. However, the eNOS chimera $\left(\mathrm{eNOS}_{\mathrm{nFNR}}\right)$ incorporates nNOS FNR module and showed similar NO synthesis activity with native eNOS.

Cytochrome $c$ and ferricyanide reductions. Both the chimera enzymes did not alter their ferricynide reducatase activies, however, they dramatically changed their cytochrome $c$ reductase activities comparing with the wild-type enzymes (Fig. 5, Table II). The CaM-free $\mathrm{nNOS}_{\mathrm{eFNR}}$ chimera showed a lower $(\sim 4 \%)$ cytochrome $c$ reductase activity than that of wild-type nNOS. On the contrary, cytochrome $c$ reductase activity of eNOS $_{\mathrm{nFNR}}$ chimera was 14 -fold higher than that of wild-type eNOS in the absence of CaM. However, its activity did not increased up on $\mathrm{CaM}$ binding.
Kinetics of flavin and heme reduction. Under anaerobic conditions, the rates of NADPH-dependent flavin and heme reduction were measured by the aid of stopped-flow spectroscopy. Fig. 6 showed the spectra traces $(485 \mathrm{~nm})$ of flavin reduction of chimera enzymes in the absence and presence $\mathrm{CaM}$ as an absorbance decrease vs. time. The traces of flavin reduction were biphasic for both chimera enzymes. The flavin reduction rate was slower in $\mathrm{nNOS}_{\mathrm{ePNR}}$ chimera than that of native nNOS both in the presence and absence of $\mathrm{CaM} / \mathrm{Ca}^{2+}$. However, in contrast, $\mathrm{eNOS}_{\mathrm{nFNR}}$ chimera showed a higher flavin reduction rate without $\mathrm{CaM} / \mathrm{Ca}^{2+}$, and it weakly increased upon $\mathrm{CaM}$ binding (Table III). These results consistent with the results acquired from steady-state cytochrome $c$ reduction. Like wild-type enzymes, both chimeras are required $\mathrm{CaM}$ binding 
for heme reduction. However, the $\mathrm{nNOS}_{\mathrm{eFNR}}$ chimera showed a lower heme reduction rate comparing with that of wild-type nNOS, and no significant change was found between NOS $_{\mathrm{nFNR}}$ and wild-type eNOS.

Clinical implication. Experimental and clinical results show that $\mathrm{NO}$ is involved in the genesis of depression as well as in antidepressant drug effects (30). NOS catalyze a two-step oxidation of L-arginine to form NO. NOS is also the molecular target of anti-inflammatory compounds (30). Inhibition of NOS activity will exert antidepressant-like effect in animal models (31). NOS chimeras have been successfully created in this work. Investigations provide a better understanding of how distinct protein structures or structural features influence the activities of NOS enzymes. Our results provide general fundamental understanding for rational design of NOS enzymes in order to regulate their functions in various biological settings (32).

The reductase domains of eNOS, nNOS and the two constitutive nitric oxide synthase (cNOS) share higher sequence similarity (over 60\%). These domains contain same regulatory peptide (a C-terminal tail and an $\mathrm{AI}$ ) and same cofactor binding sites. Nevertheless, they differ observably in the ability for transferring their electrons to heme or hemeprotein acceptors. In order to evaluate the role of FNR module in controlling NOS catalytic activities, chimeras were created by interchanging the FNR-like module between eNOS and nNOS in this work. The eNOS chimera $\left(\mathrm{eNOS}_{\mathrm{nFNR}}\right.$ ) showed a higher cytochrome $c$ reductase activity without calmodulin (CaM), and the activity was over 10-fold higher than that of native eNOS. Meanwhile, the activity did not increase upon CaM binding. The NO synthesis rate was similar to that of native eNOS. In contrast, the nNOS chimera $\left(\mathrm{nNOS}_{\mathrm{eFNR}}\right)$ had a $\sim 10 \%$ cytochrome $c$ reductase activity of native nNOS without CaM. The NO synthesis activity for $\mathrm{nNOS}$ chimera $\left(\mathrm{nNOS}_{\mathrm{eFNR}}\right)$ was $\sim 12 \%$ activity of native nNOS. The NOS FNR modules transferred their ferricyanide reductase character to the chimera enzymes. In conclusion, the FNR module is important in adjusting electrons flow through the reductase domain and out of the FMN module. Results indicated that the FNR module plays a critical role in controlling electron transfer capacities of the FMN module.

\section{Acknowledgements}

The present study was supported by 2016 Key science and technology plan project of Henan province (162102310198), the Henan province health department general project (201403046) and youth innovation fund of the first Affiliated Hospital of Zhengzhou University.

\section{References}

1. Roman LJ, Martásek P and Masters BS: Intrinsic and extrinsic modulation of nitric oxide synthase activity. Chem Rev 102: 1179-1190, 2002.

2. Stuehr DJ, Kwon NS, Nathan CF, Griffith OW, Feldman PL and Wiseman J: N omega-hydroxy-L-arginine is an intermediate in the biosynthesis of nitric oxide from L-arginine. J Biol Chem 266: 6259-6263, 1991.

3. Bredt DS, Hwang PM, Glatt CE, Lowenstein C, Reed RR and Snyder SH: Cloned and expressed nitric oxide synthase structurally resembles cytochrome P-450 reductase. Nature 351: 714-718, 1991.
4. Lamas S, Marsden PA, Li GK, Tempst P and Michel T: Endothelial nitric oxide synthase: Molecular cloning and characterization of a distinct constitutive enzyme isoform. Proc Natl Acad Sci USA 89: 6348-6352, 1992.

5. Klatt P, Schmidt K, Uray G and Mayer B: Multiple catalytic functions of brain nitric oxide synthase. Biochemical characterization, cofactor-requirement and the role of $\mathrm{N}$ omega-hydroxy-L-arginine as an intermediate. J Biol Chem 268: 14781-14787, 1993.

6. Moncada S and Higgs EA: The discovery of nitric oxide and its role in vascular biology. Br J Pharmacol 147 (Suppl 1): S193-S201, 2006.

7. Schmidt HH, Smith RM, Nakane M and Murad F: Ca2+/calmodulin-dependent NO synthase type I: A biopteroflavoprotein with $\mathrm{Ca} 2+/ \mathrm{calmodulin}$-independent diaphorase and reductase activities. Biochemistry 31: 3243-3249, 1992.

8. McMillan K, Bredt DS, Hirsch DJ, Snyder SH, Clark JE and Masters BS: Cloned, expressed rat cerebellar nitric oxide synthase contains stoichiometric amounts of heme, which binds carbon monoxide. Proc Natl Acad Sci USA 89: 11141-11145, 1992.

9. Feng C, Taiakina V, Ghosh DK, Guillemette JG and Tollin G: Intraprotein electron transfer between the FMN and heme domains in endothelial nitric oxide synthase holoenzyme. Biochim Biophys Acta 1814: 1997-2002, 2011.

10. Rozhkova EA, Fujimoto N, Sagami I, Daff SN and Shimizu T: Interactions between the isolated oxygenase and reductase domains of neuronal nitric-oxide synthase: Assessing the role of calmodulin. J Biol Chem 277: 16888-16894, 2002.

11. Daff S, Noble MA, Craig DH, Rivers SL, Chapman SK, Munro AW, Fujiwara S, Rozhkova E, Sagami I and Shimizu T: Control of electron transfer in neuronal NO synthase. Biochem Soc Trans 29: 147-152, 2001.

12. Roman LJ, Miller RT, de La Garza MA, Kim JJ and Siler Masters BS: The $\mathrm{C}$ terminus of mouse macrophage inducible nitric-oxide synthase attenuates electron flow through the flavin domain. J Biol Chem 275: 21914-21919, 2000.

13. Roman LJ, Martásek P, Miller RT, Harris DE, de La Garza MA, Shea TM, Kim JJ and Siler Masters BS: The C termini of constitutive nitric-oxide synthases control electron flow through the flavin and heme domains and affect modulation by calmodulin. J Biol Chem 275: 29225-29232, 2000.

14. Alderton WK, Cooper CE and Knowles RG: Nitric oxide synthases: Structure, function and inhibition. Biochem J 357: 593-615, 2001

15. Salerno JC, Harris DE, Irizarry K, Patel B, Morales AJ, Smith SM, Martasek P, Roman LJ, Masters BS, Jones CL, et al: An autoinhibitory control element defines calcium-regulated isoforms of nitric oxide synthase. J Biol Chem 272: 29769-29777, 1997.

16. Nishida CR and de Montellano PR: Control of electron transfer in nitric-oxide synthases. Swapping of autoinhibitory elements among nitric-oxide synthase isoforms. J Biol Chem 276: 20116-20124, 2001.

17. Daff S, Sagami I and Shimizu T: The 42-amino acid insert in the FMN domain of neuronal nitric-oxide synthase exerts control over $\mathrm{Ca}(2+) / \mathrm{calmodulin}$-dependent electron transfer. J Biol Chem 274: 30589-30595, 1999.

18. Zhang J, Martàsek P, Paschke R, Shea T, Siler Masters BS and Kim JJ: Crystal structure of the FAD/NADPH-binding domain of rat neuronal nitric-oxide synthase. Comparisons with NADPH-cytochrome P450 oxidoreductase. J Biol Chem 276: 37506-37513, 2001.

19. Matsuda $\mathrm{H}$ and Iyanagi $\mathrm{T}$ : Calmodulin activates intramolecular electron transfer between the two flavins of neuronal nitric oxide synthase flavin domain. Biochim Biophys Acta 1473: 345-355, 1999.

20. Guan ZW and Iyanagi T: Electron transfer is activated by calmodulin in the flavin domain of human neuronal nitric oxide synthase. Arch Biochem Biophys 412: 65-76, 2003.

21. Guan ZW, Kamatani D, Kimura S and Iyanagi T: Mechanistic studies on the intramolecular one-electron transfer between the two flavins in the human neuronal nitric-oxide synthase and inducible nitric-oxide synthase flavin domains. J Biol Chem 278: 30859-30868, 2003.

22. Gruez A, Pignol D, Zeghouf M, Covès J, Fontecave M, Ferrer JL and Fontecilla-Camps JC: Four crystal structures of the $60 \mathrm{kDa}$ flavoprotein monomer of the sulfite reductase indicate a disordered flavodoxin-like module. J Mol Biol 299: 199-212, 2000 . 
23. Adak S, Ghosh S, Abu-Soud HM and Stuehr DJ: Role of reductase domain cluster 1 acidic residues in neuronal nitric-oxide synthase. Characterization of the FMN-FREE enzyme. J Biol Chem 274: 22313-22320, 1999.

24. Andrew PJ and Mayer B: Enzymatic function of nitric oxide synthases. Cardiovasc Res 43: 521-531, 1999.

25. Adak S, Aulak KS and Stuehr DJ: Chimeras of nitric-oxide synthase types I and III establish fundamental correlates between heme reduction, heme-NO complex formation, and catalytic activity. J Biol Chem 276: 23246-23252, 2001.

26. Nishida CR and Ortiz de Montellano PR: Electron transfer and catalytic activity of nitric oxide synthases. Chimeric constructs of the neuronal, inducible, and endothelial isoforms. J Biol Chem 273: 5566-5571, 1998.

27. Abu-Soud HM, Ichimori K, Presta A and Stuehr DJ: Electron transfer, oxygen binding, and nitric oxide feedback inhibition in endothelial nitric-oxide synthase. J Biol Chem 275: 17349-17357, 2000 .
28. Newman E, Spratt DE, Mosher J, Cheyne B, Montgomery HJ, Wilson DL, Weinberg JB, Smith SM, Salerno JC, Ghosh DK and Guillemette JG: Differential activation of nitric-oxide synthase isozymes by calmodulin-troponin C chimeras. J Biol Chem 279: 33547-33557, 2004

29. Montgomery HJ, Perdicakis B, Fishlock D, Lajoie GA, Jervis E and Guy Guillemette J: Photo-control of nitric oxide synthase activity using a caged isoform specific inhibitor. Bioorg Med Chem 10: 1919-1927, 2002.

30. Dvorakova M and Landa P: Anti-inflammatory activity of natural stilbenoids: A review. Pharmacol Res 124: 126-145, 2017.

31. da Silva Leal VM, Bonassoli VT, Soares LM, Milani H and de Oliveira RMW: Depletion of 5 hydroxy-triptamine (5-HT) affects the antidepressant-like effect of neuronal nitric oxide synthase inhibitor in mice. Neurosci Lett 656: 131-137, 2017.

32. Wang ZQ, Haque MM, Binder K, Sharma M, Wei CC and Stuehr DJ: Engineering nitric oxide synthase chimeras to function as NO dioxygenases. J Inorg Biochem 158: 122-130, 2016. 